system as hirsute shows increased androgen metabolism in up to $90 \%$.

Both the adrenal glands and the ovaries are a source of androgens, and one classic cause of hirsutism is the polycystic ovary syndrome, first recognised as a clinical triad of amenorrhoea, hirsutism, and obesity by Stein and Leventhal in 1935..$^{3.5}$ Most women who complain of excess hair, however, are not obese, nor do they have menstrual disturbance, but Adams and others report in this issue ( $\mathrm{p} 355$ ) a high incidence of polycystic ovarian disease (as shown by modern ultrasound techniques) in a small sample of women with hirsutism and normal menses. They claim that the "idiopathic" label can now be removed from most patients. Nevertheless, small cysts may represent ovarian disease shared by several dysfunctional states, ${ }^{6}$ and, except for women complaining of infertility, they do not alter the treatment.

Amenorrhoea, oligomenorrhoea, signs of virilisation, and extensive hirsutism make referral to an endocrinologist or gynaecologist mandatory. Reassurance that a woman is endocrinologically normal may be achieved by measuring plasma androgen concentrations in the follicular phase of the menstrual cycle. A common finding will be that the concentration is at the upper end of, or just above, the normal range, ${ }^{2}$ and we do not know whether the increased metabolism of androgens within the skin and plucked hairs of hirsute women is a primary or secondary phenomenon..$^{7.9}$

Cosmetic treatments should always be advised ${ }^{10}$ : bleaching and depilatory creams are both messy and expensive; electrolysis is also expensive but useful for localised problems; and shaving and plucking are excellent methods and do not encourage increase in hair growth rate or changes in colour or diameter despite widely held beliefs to the contrary. "The difficult therapeutic issue is whether to treat specifically the minor changes in plasma androgen concentrations and tissue androgen metabolism.

Apart from the specific management of adrenal and ovarian androgenic states, the treatment options include oral antiandrogens and oestrogens in various combinations. ${ }^{12}$ I prefer a regimen of the antiandrogen cyproterone acetate combined with ethinyloestradiol. Reduction in hair growth rate, diameter, and pigmentation is usually seen in four to eight months. Cyproterone acetate works as a competitive inhibitor, and therefore relapse occurs within three to nine months of stopping the drug. ${ }^{13}$ Low dose cyproterone acetate combined with ethinyloestradiol in the preparation Diane may be useful maintenance treatment. Spironolactone is a potent antiandrogen with actions similar to those of cyproterone acetate, and combined with an oral contraceptive it has been shown in limited clinical trials to be equally effective. ${ }^{14}$ Topical antiandrogens do not work.

Women who complain to their general practitioners about excessive hair have usually tried cosmetic treatments. They have given great thought to their problem and are seeking both help and advice, and a good interview may be enough. Referral to a sympathetic hospital specialist may provide the extra reassurance of normality that the patient needs and is necessary if medical treatment is indicated. It is unfortunate that the increased complexity of techniques for investigating androgen metabolism and ovarian pathology have not been matched by the production of an effective long term treatment.

NiCK Simpson

Consultant Dermatologist,

Royal Infirmary,

Glasgow G4 0SF
1 Ferriman D, Gallwey JD. Clinical assessment of body hair growth in women. $\mathcal{f}$ Clin Endocrinol Metab 1961;21:1440-7.

Abraham GE, Chakmakjian ZH. Plasma steroids in hirsutism. Obstet Gynecol 1974;44:171-5.

3 Yen SSC. The polycystic ovary syndrome. Clin Endocrinol $(O x f)$ 1980;12:177-208.

4 Stein IF, Leventhal MC. Amenorrhoea associated with bilateral polycystic ovaries. Am $\mathcal{F}$ Obstet Gynecol 1935;29:181-91.

5 Vaitukaitis JL. Polycystic-ovary syndrome-what is it? N Engl f Med 1983;309:1245-6.

6 Franks S, Adams J, Mason H, Polson D. Ovulatory disorders in women with polycystic ovary syndrome. Clin Obstet Gynecol 1985;12:605-32.

Thomas JP, Oake RJ. Androgen metabolism in the skin of hirsute women. $\mathcal{J}$ Clin Endocrinol Metab 1974;38:19-22.

8 Kuttenn F, Mowszowicz I, Schaison G, Mauvais-Jarvis P. Androgen production and skin metabolism in hirsutism. F Endocrinol 1977;75:83-91.

9 Glickman SP, Rosenfield RL. Androgen metabolism by isolated hairs from women with idiopathic hirsutism is usually normal. $\mathcal{F}$ Invest Dermatol 1984;82:62-6.

10 Rentoul JR, Aitken AA. The cosmetic treatment of hirsutism. Practitioner 1980;224:1171-5.

11 Peereboom-Wynia JDR. The effect of various methods of depilation on density of hair growth in women with idiopathic hirsutism. Archiv für Dermatologische Forschung 1972;243:164-76.

12 Hammerstein J, Moltz L, Schwartz U. Antiandrogens in the treatment of acne and hirsutism. $\mathcal{J}$ Steroid Biochem 1983;19:591-7.

13 Underhill R, Dewhurst J. Further clinical experience in the treatment of hirsutism with cyproterone acetate. Br f Obstet Gynaecol 1979;86:139-41.

14 Chapman MG, Dowsett M, Dewhurst CJ, Jeffcoate SL. Spironolactone in combination with an oral contraceptive: an alternative treatment for hirsutism. Br J Obstel Gynaecol 1985;92:983-5.

\section{Lies, damned lies, and suppressed statistics}

Every 10 years the Registrar General produces a supplement to the national census in which deaths are analysed by occupation, cause of death, sex, and age. The latest one has just been published, and something strange has happenedreference to the social class differences in mortality have almost slipped out. ' Why is this? Could it be because somebody in the government or in the Registrar General's office is anxious to play down the widening gap in mortality between rich and poor?

If so, history is repeating itself. Six years ago a similar clumsy attempt was made to play down the Black report, which showed not only that there was a large gap in mortality between social classes $\mathrm{I}$ and $\mathrm{V}$ but also that the gap was widening. ${ }^{2}$ Instead of having the report properly printed and published the government made 260 typescripts available on August bank holiday Monday and accompanied it with a foreword from the Secretary of State stating that he had no intention of responding to its detailed recommendations. Not surprisingly, this attempt at suppression made the document instantly more newsworthy, and it has since been published by Penguin and become, in the minds of many, the most important medical report since the war. Rather the same happened with the government think tank report on alcohol: by refusing to publish it the government underlined its importance, and now anybody can buy a copy from Stockholm University. ${ }^{3}$

The previous decennial supplement was about twice as long as the new one, a sixth of the price, and had 60 or so pages devoted to discussing social class differences in mortality. ${ }^{+}$The new report, which comprises 128 pages of commentary and a set of 87 microfiches, contains only five pages on the topic. The tables on fiche represent a substantial increase over what has previously been made available and contain a wealth of data on social class. Nevertheless, anyone interested in inequalities in health will be disappointed. Although the raw data are given on fiche, the commentary gives only passing reference to the figures and then principally to emphasise their weaknesses. The report claims that the figures for social class $\mathrm{V}$ are unreliable and that we should look elsewhere for a more authoritative account of recent differences in mortality among the social classes. This 
statement is surprising enough, but even more striking is the absence of any detailed analysis of what has gone wrong and how to overcome the problems.

Saying that he has "serious reservations about the concept and use of social class classified in this way," the Registrar General ascribes these to the recent change in the classification of occupations, which are, as usual, used to classify people into the six different social classes. This change was made in 1980 to provide a better guide for census clerks, and as a result fewer people were coded to the "residual" occupational category at the census-but not at death. This, it is alleged, has had an important effect on the mortality reported for "labourers and unskilled workers," who make up a large part of social class $\mathrm{V}$.

But changes have been made to the occupational classification before-indeed, they have been made almost every decade. This is, however, the first time that no serious attempt has been made to track down the sources of the error and overcome them by using alternative groupings. Comparative bridging exercises would have enabled the old and new classification to be compared, and this decennial supplement could and should have been used to answer the question "Have inequalities in health widened?" Even if we accept the assertion that the standard mortality ratios for social class $\mathrm{V}$ are distorted by the increased precision of the new classification of occupations, the accompanying table shows that a simple and valid comparison with the figures for 1970-2 could have been made. When this is done it may be seen that

Comparison between standard mortality ratios in 1970-2 and 1979-83

\begin{tabular}{|c|c|c|c|c|c|c|}
\hline \multirow{2}{*}{$\begin{array}{l}\begin{array}{l}\text { Social } \\
\text { class }\end{array} \\
\text { I } \\
\text { II } \\
\text { III non-manual }\end{array}$} & \multicolumn{3}{|c|}{$\begin{array}{l}\text { Standard mortality } \\
\text { ratios } 1970-2\end{array}$} & \multicolumn{3}{|c|}{$\begin{array}{l}\text { Standard mortality } \\
\text { ratios for } 1979-83\end{array}$} \\
\hline & $\left.\begin{array}{l}77 \\
81 \\
99\end{array}\right\}$ & 80 & 86 & $\left.\begin{array}{l}66 \\
76 \\
94\end{array}\right\}$ & 74 & 80 \\
\hline $\begin{array}{l}\text { III manual } \\
\text { IV } \\
\text { V }\end{array}$ & $\left.\begin{array}{l}106 \\
114 \\
137\end{array}\right\}$ & 121 & 112 & $\left.\begin{array}{l}106 \\
116 \\
165\end{array}\right\}$ & 129 & 116 \\
\hline
\end{tabular}

the differentials between classes I and II and classes IV and V and those between non-manual and manual social classes have widened. The mortality of men higher up the social scale has improved and that of those lower down the scale has deteriorated.

So what can we conclude from the absence in the current decennial supplement of any attempt to analyse morbidity and mortality data by social class? It would seem that yet again the government is exerting its influence and suppressing potentially adverse information. There are precedents other than those cited above. ${ }^{5}$ For instance, the way of measuring the number of the unemployed has been changed several times in recent years, and is it coincidence that these changes have always reduced the total? The 1986 edition of Social Trends compared the amount spent on housing by owner occupiers and tenants, but showed the cost to owner occupiers before tax reliei and the cost to tenants after rebates had been deducted. The figures are thus not comparable and exaggerate the amount that owner occupiers pay. Another example was the way that ministers succeeded in having a table on unemployment and health removed from Social Trends because it did not contain a table showing the health problems of those in employment. The most recent example is the delay in publishing the analysis of families with low incomes from the family expenditure survey showing the number of families living in poverty. ${ }^{6}$ This used to be published annually, but in 1979 it was decided-on economic grounds-to publish it every other year. The analysis from the 1981 data was published in October 1983, so the analysis from the 1983 data might have been expected 10 months ago. The figures, which show that the number of people living on supplementary benefit increased from 7.6 million in 1981 to 8.8 million in 1983 , were finally "published" on the day that the House of Commons rose for the summer recess. They were placed in the library minutes before it closed.

Laurance quotes a civil servant's memorandum written in 1976 justifying not publishing figures suggesting that there were more deaths from hypothermia than people suspected: "In this politically sensitive area it is of great importance not to issue information which may be misleading and will certainly be used against the government. Any reply suggesting large numbers of old people are suffering from hypothermia could be used to put pressure on the government to increase heating provision.",

Not often are we given such direct reasons for not publishing data, but could similar considerations have led to the virtual suppression of the data on inequalities in health in the new decennial supplement?

\footnotetext{
1 Office of Population Censuses and Surveys, Occupational mortality decennial supplement England and Wales 1979-80, 82-3. London: HMSO, 1986.

Black D, Morris JN, Smith C, Townsend P. Inequalities in health. The Black report. Townsend P, Davidson N, eds. Suffolk: The Chaucer Press, 1982.

3 Central Policy Review Staff. Alcohol policies. Stockholm: Sociologista Institutionen, Stockholm University, 1979

4 Office of Population Censuses and Surveys. Occupational Mortality. Decennial supplement England and Wales 1970-2. London: HMSO, 1978.

5 Laurance J. Society in focus-How ministers fiddle figures. New Society 1986;76(Feb 28):362. 6 Department of Health and Social Security. Families with low incomes, 1981. London: HMSO, 1983.
} 